Article

\title{
A Preference Model for Supplier Selection Based on Hesitant Fuzzy Sets
}

\author{
Zhexuan Zhou ${ }^{1}$, Yajie Dou ${ }^{1, *}$, Tianjun Liao ${ }^{2}$ and Yuejin Tan ${ }^{1}$ \\ 1 College of System Engineering, National University of Defense Technology, Changsha 410073, China; \\ zhouzhexuan16@nudt.edu.cn (Z.Z.); yjtan@nudt.edu.cn (Y.T.) \\ 2 State Key Laboratory of Complex System Simulation, Beijing Institute of System Engineering, \\ 10 An Xiang Bei Li Road., Beijing, 100101, China; liaotianjun@gmail.com \\ * Correspondence: douyajie@nudt.edu.cn
}

Received: 22 January 2018; Accepted: 21 February 2018; Published: 1 March 2018

\begin{abstract}
The supplier selection problem is a widespread concern in the modern commercial economy. Ranking suppliers involves many factors and poses significant difficulties for decision makers. Supplier selection is a multi-criteria and multi-objective problem, which leads to decision makers forming their own preferences. In addition, there are both quantifiable and non-quantifiable attributes related to their preferences. To solve this problem, this paper presents a preference model based on hesitant fuzzy sets (HFS) to select suppliers. The cost and service quality of suppliers are the main considerations in the proposed model. HFS with interactive and multi-criteria decision making are used to evaluate the non-quantifiable attributes of service quality, which include competitive display, qualification ability, suitability and competitiveness of solutions, and relational fitness and dynamics. Finally, a numerical example of supplier selection for a high-end equipment manufacturer is provided to illustrate the applicability of the proposed model. The preferences of a decision maker are then analyzed by altering preference parameters.
\end{abstract}

Keywords: supplier selection; equipment manufacturer; preference relationship; hesitant fuzzy set; score function; TODIM

\section{Introduction}

Supplier selection is a hot issue in many industries. It is an important part of the procurement process, which is strongly related to the core competitiveness of enterprises [1]. The choice of a supplier is directly related to the costs of a business, quality of a product, and customer response time. With continuing manufacturing development, supplier demand is steadily increasing. As a result, the competition between suppliers is becoming increasingly intense. Decision makers often consider various factors, such as cost, product quality, lead time, and risk appetite, when selecting a supplier. Considering these indexes, the problem of supplier selection is a multi-objective and multi-criteria decision-making (MCDM) problem.

Significant research has been performed on supplier selection. AM Groot [2] defined an economic order quantity (EOQ) model for ordering goods and Disktion [3] summarized 23 criteria for supplier selection for procurement. Some of these criteria are related to the quality, cost, and delivery of products. For modelling supplier selection, several scholars have researched multi-objective decision-making and MCDM methods [4,5]. Birsen et al. [5] used a multi-objective model to assess supplier quality, cost, and product lead time. Buffa and Jackson [6] primarily focused on supplier cost, product quality, and services for multi-objective planning. Ghodsypour and O'Brien [7] used the analytic hierarchy process (AHP) to find the largest integrated value of a candidate supplier, then ranked suppliers based on that value. James [8] improved supply chain management by using a new integrated manufacturing enterprise system based on parking and forwarding algorithms, RFID, and a Markov decision process. 
Supplier selection is an MCDM problem. Dae-Ho Byun [9] used the AHP to analyze suppliers in the Korean automobile industry. Tam and Tummala [10] considered several criteria for supplier selection for communication devices. Recently, supplier selection has seen a few new developments. Tadić et al. [11] used a fuzzy version of the technique for order of preference by similarity to ideal solution (TOPSIS) to rank medical device suppliers. Yu et al. [12] built a model to select a supplier for closed-loop logistics systems using hesitant fuzzy sets. Zhou [13] evaluated supplier performance using triangular fuzzy information. Gupta et al. [14] solved the supplier selection problem using a modified intuitionistic fuzzy superiority and inferiority ranking approach. Cao et al. [15] used an integrated multi-criterion decision-making method to evaluate green suppliers. Bohner and Minner [16] analyzed supplier selection in terms of risk of failure, quantity, and business volume discounts. Wan et al. [17] presented a novel hybrid MCDM method with two-level criteria in an interval 2-tuple linguistic environment to find superior suppliers. A hybrid model with AHP and TOPSIS was presented to select the most appropriate tomography equipment [18]. Zhao [19] proposed a hybrid MCDM Method for sustainability to selected green supplier of thermal power equipment. An Integrated MCDM Model was used to select mining method in presence of uncertainty with FAHP and FTOPSIS [20]. A fuzzy ISM (Fuzzy Interpretive Structural Modelling) with AHP and fuzzy PROMETHEE (Preference Ranking Organization Method for Enrichment Evaluation) was used to build the interdependence of supply chain complexity management [21].

However, in the above studies on supplier selection, either supplier-explicit criteria attributes were considered or non-quantifiable attributes were considered, but not both. To date, there has been no research that considers combining quantifiable attributes and non-quantifiable attributes within an objective. Furthermore, decision makers were only considered in the design of the model and their psychological decision-making behavior was not considered. However, in a real-world supplier selection process, there may be hesitation or personal preferences for certain attributes based on individual reasoning. To better reflect these influences, this paper proposes a multi-objective preference model using hesitant fuzzy sets (HFS). Additionally, the service quality of suppliers is evaluated using interactive and multi-criteria decision making (TODIM), which better represents real-world decision-making processes. This was the major research motivation for this study.

Zadeh first proposed the fuzzy set in 1965 [22] and used it to solve multiple attribute decision-making problems in 1970 [23]. Since then, many researchers have explored the use of fuzzy sets in decision making. Recently, Torra [24] proposed an important form of fuzzy sets called HFS. Xu and Xia [25] then gave the HFS a mathematical form and defined related operations. Farhadinia [26,27] proposed a series of scoring functions and a ranking method for hesitant fuzzy numbers. HFS play an important role in decision making. Zhang and $\mathrm{Xu}$ [28] proposed a novel measuring function for hesitant fuzzy numbers and used the function in TODIM. Zhang and Xu also used HFS in a qualitative flexible multiple criteria method with a signed distance-based comparison method [29] and TOPSIS with incomplete weight information [30]. Novel distance and similarity measures have also been used for clustering analysis in a hesitant fuzzy environment [31]. In another study, Ai et al. [32] developed dependent hesitant fuzzy aggregation operators to apply to multiple attribute group decision making. Tang [33] solved the green supplier selection problem with hesitant fuzzy information. Based on the above studies, one can see that HFS are good tools to describe non-quantitative decision-making properties, which better represent real-world decision-making processes. Therefore, this paper proposes a preference model with multiple objectives that integrates HFS and TODIM.

The primary focus of this study was building a preference decision-making model and solving the supplier selection problem using HFS. In the proposed model, the cost and service quality of suppliers are considered to reflect decision maker preferences. To evaluate the service quality of a supplier efficiently, HFS are used to describe the evaluations of experts. During service quality evaluation, a hesitant fuzzy number score function is analyzed and TODIM is employed to evaluate the individual 
behavior of decision makers. Finally, a numerical supplier selection example is provided to illustrate the advantages of the proposed method.

The remainder of this paper is organized as follows. Section 2 presents the preference model for supplier selection considering cost and service quality. Section 3 contains an evaluation of supplier service quality using HFS with TODIM. Section 4 presents a case study on high-end equipment supplier selection. Section 5 contains analysis of the influence of different preferences on decision making. Section 6 presents a final discussion and summary of this study.

\section{Preference Models for Supplier Selection}

The topic of supplier selection has been extensively studied by researchers. In existing supplier selection methods, most of the factors considered are quantifiable (e.g., cost). Quantitative and non-quantitative factors are rarely considered simultaneously. This study considers both the minimum cost of suppliers and service quality of suppliers. Therefore, the following multi-objective model (Model-1) is established, with the goal of finding both the smallest cost and best quality of service. Let $C_{i}$ and $Q_{i}$ represent the cost and service quality, respectively, of suppliers.

Model-1

$$
\left\{\begin{array}{c}
\min C_{i} \\
\max Q_{i}
\end{array}\right.
$$

Multi-objective problem-solving processes are complex and typically contain various obstacles. In real-world situations, decision-making results tend to be accompanied by decision-maker preferences. These preferences play a pivotal role in decision-making. This is an issue that previous multi-objective models for supplier selection have not adequately solved. Based on this consideration, this paper presents a preference model for supplier selection. To make the preference objective consistent, Equation (2) is used to standardize the data.

$$
\left\{\begin{aligned}
C_{i}^{\prime} & =\frac{\min C_{i}}{C_{i}} \\
Q_{i}^{\prime} & =\frac{Q_{i}}{\max Q_{i}}
\end{aligned}\right.
$$

From the above formula, $C_{i}{ }^{\prime}$ and $Q_{i}{ }^{\prime}$ are the standardized cost and service quality, respectively. They are considered to be better when they have larger values. The preference parameter $\tau$ is introduced and Model-1 is transformed into Model-2.

Model-2

$$
\max V_{i}=\tau C_{i}^{\prime}+(1-\tau) Q_{i}^{\prime}
$$

where $V_{i}$ is the ranking value of suppliers, and $\tau \in[0,1]$. When $1 \geq \tau>0.5$, the decision maker has a cost preference and pursues the lowest possible cost, even to the detriment of service quality. When $\tau=0.5$, the decision maker is neutral and when $0 \leq \tau<0.5$, the decision maker has a service preference and pursues the highest quality, regardless of the cost.

HFS are introduced to describe non-quantifiable service quality. Attributes of service quality evaluation for suppliers were used in [34], which included competitive display $a_{1}$, qualification ability $a_{2}$, suitability and competitiveness of solutions $a_{3}$, and relational fitness and dynamics $a_{4}$. The attributes of supplier service quality are listed in Table 1. The factor of "risk" is one of the important roles in manufacturing activity [35], and especially when selecting suppliers. In this model, the risk is included in the Supplier Service Quality Attribute (suitability and competitiveness of solutions $a_{3}$ ). 
Table 1. Supplier Service Quality Attribute Description.

\begin{tabular}{ll}
\hline Attributes & Description \\
\hline Competitive display $a_{1}$ & $\begin{array}{l}\text { Personnel, business processes, technology, business certification, } \\
\text { innovation records }\end{array}$ \\
Qualification ability $a_{2}$ & $\begin{array}{l}\text { Financial stability, infrastructure and resources, management } \\
\text { systems, and service stability }\end{array}$ \\
The suitability and competitiveness of Solutions $a_{3}$ & $\begin{array}{l}\text { Solutions, service provision, risk sharing, terms, } \\
\text { human resource requirements } \\
\text { Telational fitness and dynamic } a_{4}\end{array}$ \\
$\begin{array}{l}\text { Team culture, team management, relative importance, existing } \\
\text { achievements }\end{array}$ \\
\hline
\end{tabular}

\section{Supplier Service Quality Evaluation Based on HFS with TODIM}

\subsection{Hesitant Fuzzy Sets}

\subsubsection{Preliminaries}

Quality of service is typically not accurately quantified. In this study, HFS are used to describe the service quality of a supplier. In real-world decision-making processes, people typically use hesitant fuzzy information to represent preference evaluations. Recently, Xia and Xu [25] defined HFS that include the membership and non-membership degrees of several different values.

Definition 1 ([25]). HFS can be defined as

$$
H=\left\{<x, h_{A}(x)>\mid x \in X\right\}
$$

where $h_{H}(x)$ takes on real values in the range $[0,1]$. This value represents the degree of possibility that element $x$ belongs to $X$ in set $A$. Xia and $X u$ [25] defined $h_{H}(x)$ as a hesitant fuzzy number.

Definition 2 ([24,25]). According to the definition of a hesitant fuzzy number, the following operation can be derived. Suppose that there are three hesitant fuzzy numbers $h_{1}, h_{2}$, and $h_{3}$. Then, the following is true:

$$
\begin{array}{ll}
\text { (1) } & h_{1} \oplus h_{2}=H\left\{\left(\gamma_{1}+\gamma_{2}-\gamma_{1} \gamma_{2}\right) \mid \gamma_{1} \in h_{1}, \gamma_{2} \in h_{2}\right\} \\
\text { (2) } & h_{1} \otimes h_{2}=H\left\{\gamma_{1} \gamma_{2} \mid \gamma_{1} \in h_{1}, \gamma_{2} \in h_{2}\right\} \\
\text { (3) } & \lambda h=H\left\{1-(1-\gamma)^{\lambda} \mid \gamma \in h\right\}(\lambda>0) \\
\text { (4) } & h^{\lambda}=H\left\{\gamma^{\lambda} \mid \gamma \in h\right\}(\lambda>0) \\
\text { (5) } & h^{C}=H\{1-\gamma \mid \gamma \in h\}
\end{array}
$$

Hypothesis 1 ([36]). To calculate the distance between two hesitant fuzzy numbers or compare them conveniently, the hesitant number with fewer elements should be extended until all hesitant numbers have the same number of elements. If the decision maker is pursuing risk, then the largest element of hesitation should be added to all corresponding elements until the two hesitant fuzzy numbers are equal, and vice versa.

\subsubsection{Hesitant Fuzzy Number Score Function Analysis}

In the process of hesitant fuzzy multi-attribute decision-making, ranking hesitant numbers is a very important step. Xia and $\mathrm{Xu}$ [25] first defined a scoring function for hesitant fuzzy numbers. Farhadinia [26] later proposed an improved hesitant fuzzy scoring function. Recently, Zhang [28] proposed a novel hesitant fuzzy scoring function that only requires one step to rank hesitant fuzzy numbers. However, this method requires analysis of parameters. Therefore, a geometric hesitant fuzzy scoring function is analyzed and considered in conjunction with a mathematical geometric mean. 
Definition 3 ([27]). If there is a hesitant fuzzy number $h=\left\{\gamma^{1}, \gamma^{2}, \ldots, \gamma^{n}\right\}$, then a geometric hesitant fuzzy scoring function $S(h)$ can be defined as

$$
S(h)=\sqrt[n]{\prod_{i=1}^{n} \gamma^{i}}=\left(\gamma^{1} \times \gamma^{2}, \ldots, \times \gamma^{n}\right)^{1 / n}
$$

From this geometric scoring function, the following properties can be derived:

Property 1. For any hesitant fuzzy number $h=\left\{\gamma^{1}, \gamma^{2}, \ldots, \gamma^{n}\right\}$, its geometric hesitant fuzzy scoring function value $S(h) \in[0,1]$.

Proof. Let $\gamma^{+}=\max \left\{\gamma^{\lambda} \mid \lambda=1,2, \ldots, n\right\}$ and $\gamma^{-}=\min \left\{\gamma^{\lambda} \mid \lambda=1,2, \ldots, n\right\}$. Because

$$
\begin{gathered}
\gamma^{\lambda} \in[0,1](\lambda=1,2, \ldots, n), \\
S(h)=\sqrt[n]{\prod_{i=1}^{n} \gamma^{i}}=\left(\gamma^{1} \times \gamma^{2}, \ldots, \times \gamma^{n}\right)^{1 / n} \leq\left(\gamma^{+} \times \gamma^{+}, \ldots, \times \gamma^{+}\right)^{1 / n}=\sqrt[n]{\left(\gamma^{+}\right)^{n}}=\gamma^{+} \leq 1
\end{gathered}
$$

and

$$
\begin{gathered}
S(h)=\sqrt[n]{\prod_{i=1}^{n} \gamma^{i}}=\left(\gamma^{1} \times \gamma^{2}, \ldots, \times \gamma^{n}\right)^{1 / n} \leq\left(\gamma^{-} \times \gamma^{-}, \ldots, \times \gamma^{-}\right)^{1 / n} \\
=\sqrt[n]{\left(\gamma^{-}\right)^{n}}=\gamma^{-} \geq 0 .
\end{gathered}
$$

Therefore, $0 \leq S(h) \leq 1$.

Property 2. If $h_{1}=\left\{\gamma_{1}^{1}, \gamma_{1}^{2}, \ldots, \gamma_{1}^{n}\right\}$ and $h_{2}=\left\{\gamma_{2}^{1}, \gamma_{2}^{2}, \ldots, \gamma_{2}^{n}\right\}$ are both hesitant fuzzy numbers, their internal elements are arranged in ascending order and their elements are equal. Therefore, if $\gamma_{1}^{1} \leq \gamma_{2}^{1}, \gamma_{1}^{2} \leq \gamma_{2}^{2}, \ldots$, and $\gamma_{1}^{n} \leq \gamma_{2}^{n}$, then:

$$
S\left(h_{1}\right) \leq S\left(h_{2}\right)
$$

Proof. Because $\gamma_{1}^{n} \leq \gamma_{2}^{n}$, it follows that

$$
\sqrt[n]{\prod_{i=1}^{n} \gamma_{1}{ }^{i}}=\left(\gamma_{1}{ }^{1} \times \gamma_{1}{ }^{2}, \ldots, \times \gamma_{1}{ }^{n}\right)^{1 / n} \leq \sqrt[n]{\prod_{i=1}^{n} \gamma_{2}{ }^{i}}=\left(\gamma_{2}{ }^{1} \times \gamma_{2}{ }^{2}, \ldots, \times \gamma_{2}{ }^{n}\right)^{1 / n} .
$$

Therefore, $S\left(h_{1}\right) \leq S\left(h_{2}\right)$.

For this geometric hesitant fuzzy scoring function, a hesitant fuzzy number ranking method is described as follows:

Definition 4. If there are two hesitant fuzzy numbers $h_{1}$ and $h_{2}$, according to (5), a new ranking method can be defined as follows:

(1) If $S\left(h_{1}\right)>S\left(h_{2}\right)$, then $h_{1}$ is superior to $h_{2}$ and $h_{1} \succ h_{2}$.

(2) If $S\left(h_{1}\right)=S\left(h_{2}\right)$, then $h_{1}$ is equal to $h_{2}$ and $h_{1} \sim h_{2}$.

(3) If $S\left(h_{1}\right)<S\left(h_{2}\right)$, then $h_{1}$ is inferior to $h_{2}$ and $h_{1} \prec h_{2}$.

To illustrate the usability of the proposed ranking method, the following example is presented [37]: There are three hesitant numbers

$$
h_{1}=\{0.3,0.5\}, h_{2}=\{0.4\} \text {, and } h_{2}=\{0.2,0.4,0.6\} .
$$


Different ranking methods are used to rank them.

According to the geometric scoring function (5), $S\left(h_{1}\right)=0.3873, S\left(h_{2}\right)=0.4000$, and $S\left(h_{3}\right)=$ 0.3634. Therefore,

$$
h_{2} \succ h_{1} \succ h_{3} \text {. }
$$

The comparison results of the ranking methods are listed in Table 2.

Table 2. Results of the different ranking methods.

\begin{tabular}{ccc}
\hline Ranking Methods & Score Value & Order \\
\hline Xia and Xu [25] & $S\left(h_{1}\right)=S\left(h_{2}\right)=S\left(h_{3}\right)=0.4$ & $h_{1} \sim h_{2} \sim h_{3}$ \\
Farhadinia [26] & $S\left(h_{1}\right)=0.467, S\left(h_{2}\right)=0.4, S\left(h_{3}\right)=0.467$ & $h_{1} \sim h_{3} \succ h_{2}$ \\
Liao and Xu [38] & $S\left(h_{1}\right)=S\left(h_{2}\right)=S\left(h_{3}\right)=0.4$ & $h_{2} \succ h_{1} \succ h_{3}$ \\
Zhang $(\delta=0.1)$ [28] & $S\left(h_{1}\right)=0.1, v\left(h_{2}\right)=0, v\left(h_{3}\right)=0.1633$ & $h_{2} \succ h_{1} \succ h_{3}$ \\
This study & $S\left(h_{1}\right)=0.3886, S\left(h_{2}\right)=0.4, S\left(h_{3}\right)=0.3672$ & $h_{2} \succ h_{1} \succ h_{3}$ \\
\hline
\end{tabular}

It can be seen from Table 2 that the ranking method of Xia and $\mathrm{Xu}$ [25] cannot distinguish between the three hesitant fuzzy numbers. The method from Farhadinia [26] cannot distinguish between $h_{1}$ and $h_{2}$. The results of the geometric hesitant fuzzy scoring function are the same as those of the methods from Liao and $\mathrm{Xu}$ [38], and Zhang [28]. However, the method from Liao and Xu [38] is computationally complex and the method from Zhang [28] requires analysis of the parameter $\delta$. Therefore, the geometric hesitant fuzzy scoring function is superior to the other ranking methods.

\subsection{TODIM}

The psychological factors of decision makers often play a major role in the process of multi-attribute decision-making. The proposed method selects suppliers by incorporating the preferences of decision makers in the selection process. By using TODIM, the proposed model considers the mentality of decision makers in the evaluation of supplier service quality. Additionally, a hesitant fuzzy number is used to describe the evaluation value, which results in a more objective description of supplier service quality.

Assume that there are $m$ candidate suppliers and $n$ attributes. A decision matrix is then constructed as $\left(a_{i j}\right)_{m \times n^{\prime}}$, where $a_{i}$ are the attributes of suppliers and $x_{i}$ are candidate suppliers. Let $w$ be the weight of the attributes and $a_{m}$ be the attribute with the largest weight. Then, let $a_{m}$ be a reference attribute, where the reference weights of the other attributes for $a_{m}$ are:

$$
w_{j m}=\frac{w_{j}}{w_{m}}, j=1,2, \ldots, n
$$

Then, the perceived value function of supplier $x_{i}$ to $x_{k}$ can be defined as

$$
\vartheta\left(x_{i}, x_{k}\right)=\sum_{j=1}^{n} \varphi\left(x_{i}, x_{k}\right), i, k=1,2, \ldots, m
$$

where

$$
\varphi\left(x_{i}, x_{k}\right)=\left\{\begin{array}{cc}
\sqrt{w_{j m} d\left(h_{i j}, h_{k j}\right) / \sum_{j=1}^{n} w_{j m},} & \text { if } S\left(h_{i j}\right)>S\left(h_{k j}\right) \\
0, & \text { if } S\left(h_{i j}\right)=S\left(h_{k j}\right) \\
-\frac{1}{\theta} \sqrt{\left(\sum_{j=1}^{n} w_{j m}\right) d\left(h_{i j}, h_{k j}\right) / w_{j m},} & \text { if } S\left(h_{i j}\right)<S\left(h_{k j}\right)
\end{array}\right.
$$

Here, $\theta$ represents the loss avoidance coefficient and 


$$
d\left(h_{i j}, h_{k j}\right)=\sqrt{\frac{1}{n} \sum_{\lambda=1}^{n}\left(\gamma_{i j}^{\lambda}-\gamma_{k j}^{\lambda}\right)^{2}}
$$

is the Euclidean distance from $h_{i j}$ to $h_{k j}$.

In (8), there are three possibilities: $S\left(h_{i j}\right)>S\left(h_{k j}\right)$ is beneficial, $S\left(h_{i j}\right)=S\left(h_{k j}\right)$ is neutral, or $S\left(h_{i j}\right)<S\left(h_{k j}\right)$ represents a loss.

Therefore, a general perceived value function for the service quality of supplier $x_{i}(i=1,2, \ldots, m)$ can be defined as

$$
\Phi\left(x_{i}\right)=\frac{\sum_{k=1}^{m} \vartheta\left(x_{i}, x_{k}\right)-\min _{i}\left\{\sum_{k=1}^{m} \vartheta\left(x_{i}, x_{k}\right)\right\}}{\max _{i}\left\{\sum_{k=1}^{m} \vartheta\left(x_{i}, x_{k}\right)\right\}-\min _{i}\left\{\sum_{k=1}^{m} \vartheta\left(x_{i}, x_{k}\right)\right\}}, i=1,2, \ldots, m .
$$

The steps for supplier service quality evaluation based on HFS with TODIM can then be defined as follows:

Step 1: HFS are used to describe the evaluation matrix $\left(a_{i j}\right)_{m \times n}$ of supplier service quality.

Step 2: The relationship between the pros and cons of each pair of attributes can be calculated using the geometric hesitant fuzzy scoring function (5).

Step 3: Equation (8) is used to calculate the perceived value $\vartheta\left(x_{i}, x_{k}\right)$ of every supplier.

Step 4: Then, the generalized perceived value $\Phi\left(x_{i}\right)$ for supplier service quality can be calculated using Equation (10).

\section{Case Study}

With continued economic development, the selection of suppliers has become an important issue in the manufacturing industry. This study analyzes supplier selection based on both cost and quality of service. In a world of intelligent systems, intelligent manufacturing plays a major role and the core pillar of manufacturing is a wide range of high-end equipment. There are three major facets of the high-end equipment manufacturing industry: First, there is significant technological content, including performance of knowledge, technology intensity, and multi-disciplinary technology. Second, high-end value chains with high value-added features. Third, its position at the core of the industry chain and its level of development, which determines the overall competitiveness of the industry chain. Therefore, the selection of high-end equipment manufacturing suppliers is very important.

In this case, study, there are four high-end equipment part suppliers and a high-end equipment manufacturer that wants to select the best supplier. To select the right supplier for the high-end equipment manufacturing industry, a multi-object model is built to analyze the suppliers in terms of cost and service quality. The costs of the suppliers are listed in Table 3. The attributes of supplier service quality [34] include competitive display $a_{1}$, qualification ability $a_{2}$, suitability and competitiveness of solutions $a_{3}$, and relational fitness and dynamics $a_{4}$. The attributes of supplier service quality are described in detail in Table 1 . The weight vector for the attributes is $(0.2,0.1,0.4,0.3)$, which is consistent with research by Gad J. Selig [34]. Considering the preferences and knowledge of the decision-maker, a hesitant fuzzy number is used to describe the evaluation values for the four suppliers under each attribute. The constructed decision matrix is presented in Table 4.

Table 3. Cost of suppliers.

\begin{tabular}{ccccc}
\hline Cost & $\mathrm{C}_{1}$ & $\mathrm{C}_{2}$ & $\mathrm{C}_{3}$ & $\mathrm{C}_{4}$ \\
\hline & 1000 & 1500 & 2000 & 1200 \\
\hline
\end{tabular}


Table 4. Hesitant fuzzy decision matrix.

\begin{tabular}{ccccc}
\hline & $\boldsymbol{a}_{\mathbf{1}}$ & $\boldsymbol{a}_{\mathbf{2}}$ & $\boldsymbol{a}_{\mathbf{3}}$ & $\boldsymbol{a}_{\mathbf{4}}$ \\
\hline$x_{1}$ & $\mathrm{H}\{0.55,0.6\}$ & $\mathrm{H}\{0.6,0.7\}$ & $\mathrm{H}\{0.5,0.7,0.75\}$ & $\mathrm{H}\{0.6,0.8,0.85\}$ \\
$x_{2}$ & $\mathrm{H}\{0.5,0.7,0.8\}$ & $\mathrm{H}\{0.4,0.6\}$ & $\mathrm{H}\{0.5,0.8\}$ & $\mathrm{H}\{0.7,0.8\}$ \\
$x_{3}$ & $\mathrm{H}\{0.55,0.7\}$ & $\mathrm{H}\{0.65,0.8\}$ & $\mathrm{H}\{0.7,0.8\}$ & $\mathrm{H}\{0.6,0.7,0.9\}$ \\
$x_{4}$ & $\mathrm{H}\{0.6,0.8\}$ & $\mathrm{H}\{0.7,0.9\}$ & $\mathrm{H}\{0.5,0.6,0.8\}$ & $\mathrm{H}\{0.8,0.9\}$ \\
\hline
\end{tabular}

In Table $4, \mathrm{H}\{0.55,0.6\}$ indicates that the decision maker has two opinions regarding supplier $x_{1}$ under the attribute $a_{1}$ and that the value may be 0.55 or 0.6 . The other data follows the same pattern.

From Equation (5), each hesitant fuzzy number scoring value can be calculated, and each supplier can be compared to the other suppliers under each attribute. Let $S$ represent a supplier being superior and I represent a supplier being inferior. For example, the hesitant fuzzy number scoring value of supplier $x_{1}$ under attribute $a_{1}$ is $S_{11}=0.574$ and the scoring value of $x_{2}$ is $S_{21}=0.6542$. Therefore, $\mathrm{S}_{11}<\mathrm{S}_{21}$, meaning this relationship can be described by $\mathrm{I}$. The score values were in Table 5 and the relationships listed in Table 6 were calculated from the score values.

Table 5. Scoring values of the hesitant fuzzy numbers.

\begin{tabular}{ccccc}
\hline & \multicolumn{1}{c}{$\boldsymbol{a}_{\mathbf{1}}$} & $\boldsymbol{a}_{\mathbf{2}}$ & $\boldsymbol{a}_{\mathbf{3}}$ & $\boldsymbol{a}_{\mathbf{4}}$ \\
\hline$x_{1}$ & $\mathrm{~S}_{11}=0.574$ & $\mathrm{~S}_{12}=0.6481$ & $\mathrm{~S}_{13}=0.6403$ & $\mathrm{~S}_{14}=0.7417$ \\
$x_{2}$ & $\mathrm{~S}_{21}=0.6542$ & $\mathrm{~S}_{22}=0.4899$ & $\mathrm{~S}_{23}=0.6325$ & $\mathrm{~S}_{24}=0.7486$ \\
$x_{3}$ & $\mathrm{~S}_{31}=0.6205$ & $\mathrm{~S}_{32}=0.7211$ & $\mathrm{~S}_{33}=0.7483$ & $\mathrm{~S}_{34}=0.7230$ \\
$x_{4}$ & $\mathrm{~S}_{41}=0.6928$ & $\mathrm{~S}_{42}=0.7937$ & $\mathrm{~S}_{43}=0.6214$ & $\mathrm{~S}_{44}=0.8485$ \\
\hline
\end{tabular}

Table 6. The relationships "superior-inferior" of suppliers.

\begin{tabular}{ccccccc}
\hline & $x_{1} / x_{2}$ & $x_{1} / x_{2}$ & $x_{1} / x_{4}$ & $x_{2} / x_{3}$ & $x_{2} / x_{4}$ & $x_{3} / x_{4}$ \\
\hline$a_{1}$ & $\mathrm{I}$ & $\mathrm{I}$ & $\mathrm{I}$ & $\mathrm{S}$ & $\mathrm{I}$ & $\mathrm{I}$ \\
$a_{2}$ & $\mathrm{~S}$ & $\mathrm{I}$ & $\mathrm{I}$ & $\mathrm{I}$ & $\mathrm{I}$ & $\mathrm{I}$ \\
$a_{3}$ & $\mathrm{~S}$ & $\mathrm{I}$ & $\mathrm{S}$ & $\mathrm{I}$ & $\mathrm{S}$ & $\mathrm{S}$ \\
$a_{4}$ & $\mathrm{I}$ & $\mathrm{I}$ & $\mathrm{I}$ & $\mathrm{S}$ & $\mathrm{I}$ & $\mathrm{I}$ \\
\hline
\end{tabular}

To calculate the distances between the hesitant fuzzy numbers in Table 4, the hesitant fuzzy numbers can be extended according to Hypothesis 1 . Therefore, the previous decision matrix is translated into the new decision matrix presented in Table 7.

Table 7. The extended hesitant fuzzy matrix.

\begin{tabular}{ccccc}
\hline & $a_{1}$ & $a_{2}$ & $a_{3}$ & $a_{4}$ \\
\hline$x_{1}$ & $\mathrm{H}\{0.55,0.55,0.6\}$ & $\mathrm{H}\{0.6,0.6,0.7\}$ & $\mathrm{H}\{0.5,0.7,0.75\}$ & $\mathrm{H}\{0.6,0.8,0.85\}$ \\
$x_{2}$ & $\mathrm{H}\{0.5,0.7,0.8\}$ & $\mathrm{H}\{0.4,0.4,0.6\}$ & $\mathrm{H}\{0.5,0.5,0.8\}$ & $\mathrm{H}\{0.7,0.7,0.8\}$ \\
$x_{3}$ & $\mathrm{H}\{0.55,0.55,0.7\}$ & $\mathrm{H}\{0.65,0.65,0.8\}$ & $\mathrm{H}\{0.7,0.7,0.8\}$ & $\mathrm{H}\{0.6,0.7,0.9\}$ \\
$x_{4}$ & $\mathrm{H}\{0.6,0.6,0.8\}$ & $\mathrm{H}\{0.7,0.7,0.9\}$ & $\mathrm{H}\{0.5,0.6,0.8\}$ & $\mathrm{H}\{0.8,0.8,0.9\}$ \\
\hline
\end{tabular}

Then, the perceived value function $\vartheta\left(x_{i}, x_{k}\right)$ of supplier $x_{i}(i=1,2,3,4)$ to supplier $x_{k}(k=1,2,3,4)$ under the same attribute $a_{j}$ can be calculated using Equation (7). Here, the loss avoidance coefficient is $\theta=1$ [39]. The results of these operations can be found in Table 8 . 
Table 8. The perceived values function value of each supplier.

\begin{tabular}{|c|c|c|c|c|c|c|c|c|c|}
\hline \multicolumn{6}{|c|}{$a_{1}$} & \multicolumn{4}{|c|}{$a_{2}$} \\
\hline & $x_{1}$ & $x_{2}$ & $x_{3}$ & $x_{4}$ & & $x_{1}$ & $x_{2}$ & $x_{3}$ & $x_{4}$ \\
\hline$x_{1}$ & 0 & -0.8579 & -0.5373 & -0.7825 & $x_{1}$ & 0 & 0.1316 & -0.8409 & -1.1892 \\
\hline$x_{2}$ & 0.1716 & 0 & 0.147 & -0.6389 & $x_{2}$ & -1.3161 & 0 & -1.5314 & -1.7321 \\
\hline$x_{3}$ & 0.1075 & -0.7349 & 0 & -0.5946 & $x_{3}$ & 0.0841 & 0.1531 & 0 & -0.8409 \\
\hline$x_{4}$ & 0.1565 & 0.1278 & 0.1189 & 0 & $x_{4}$ & 0.1189 & 0.1732 & 0.0841 & 0 \\
\hline \multicolumn{6}{|c|}{$a_{3}$} & \multicolumn{4}{|c|}{$a_{4}$} \\
\hline & $x_{1}$ & $x_{2}$ & $x_{3}$ & $x_{4}$ & & $x_{1}$ & $x_{2}$ & $x_{3}$ & $x_{4}$ \\
\hline$x_{1}$ & 0 & 0.2182 & -0.5455 & 0.1607 & $x_{1}$ & 0 & -0.5373 & -0.4639 & -0.664 \\
\hline$x_{2}$ & -0.5455 & 0 & -0.6389 & -0.3799 & $x_{2}$ & 0.1612 & 0 & 0.1565 & -0.5774 \\
\hline$x_{3}$ & 0.2182 & 0.2556 & 0 & 0.2272 & $x_{3}$ & 0.1392 & -0.5217 & 0 & -0.656 \\
\hline$x_{4}$ & -0.4017 & 0.152 & 0.5681 & 0 & $x_{4}$ & 0.1992 & 0.1732 & 0.1968 & 0 \\
\hline
\end{tabular}

The perceived value function values for each supplier under all attributes can be integrated using Equation (8). The results are listed in Table 9.

Table 9. The general perceived value function value for suppliers' service quality.

\begin{tabular}{ccccc}
\hline & $x_{1}$ & $x_{2}$ & $x_{3}$ & $x_{4}$ \\
\hline$x_{1}$ & 0 & -1.0454 & -2.3876 & -2.475 \\
$x_{2}$ & -1.5288 & 0 & -1.8668 & -3.3283 \\
$x_{3}$ & 0.549 & -0.8479 & 0 & -1.8643 \\
$x_{4}$ & 0.0729 & 0.6262 & 0.9679 & 0 \\
\hline
\end{tabular}

The general perceived value functions $\Phi\left(x_{i}\right)$ for service quality can be obtained using Equation (10):

$$
\Phi\left(x_{1}\right)=0.0972, \Phi\left(x_{2}\right)=0, \Phi\left(x_{3}\right)=0.5435, \Phi\left(x_{4}\right)=1 .
$$

Through the above steps, the general perception function values of supplier quality of service are calculated. When considering the psychological factors of decision makers, this result more closely describes the service quality of suppliers, which provides an important basis for supplier selection. The best supplier will then be selected based on the proposed preference model for multi-objective decision making.

The cost is standardized using Equation (2):

$$
C_{1}^{\prime}=1, C_{2}^{\prime}=0.667, C_{2}^{\prime}=0.5, C_{4}^{\prime}=0.8333
$$

The supplier service qualities are determined by

$$
Q_{1}^{\prime}=\Phi\left(x_{1}\right)=0.0972, Q_{2}^{\prime}=\Phi\left(x_{2}\right)=0, Q_{3}^{\prime} \Phi\left(x_{3}\right)=0.5435, Q_{4}^{\prime}=\Phi\left(x_{4}\right)=1 .
$$

Here, the decision maker has a cost preference, so the preference parameter is set to $\tau=0.7$. According to Equation (3), the final value for each supplier is calculated as follows:

$$
V_{1}=0.7291, V_{2}=0.4669, V_{3}=0.5131, V_{4}=0.8833
$$

The final ranking of the four suppliers is $V_{4} \succ V_{1} \succ V_{3} \succ V_{2}$.

Through the proposed preference model, the cost and service quality of suppliers has been considered. When the decision maker has a cost preference, supplier $x_{4}$ ranks highest and supplier $x_{2}$ ranks the lowest. Therefore, supplier $x_{4}$ is the best selection for the high-end equipment manufacturer.

$$
V_{4} \succ V_{1} \succ V_{3} \succ V_{2}
$$




\section{Preference Analysis}

Preference relationships are widely used in multi-attribute decision-making problems. During real-world decision-making processes, the result is not determined entirely from the decision-making model and most of the decision-making results are determined by the personal preferences of the decision maker. In particular, in the selection process for suppliers, many attributes are considered and many goals are optimized. As a result, the preferences of decision makers play a vital role. This study considers supplier cost and service quality, builds a preference model, and introduces the preference relation parameter $\tau \in[0,1]$. The example in Section 4 analyzed the influence of differing preferences of the decision maker on Model-2. The results of analysis are listed in Table 10.

Table 10. Supplier preference analysis.

\begin{tabular}{cccccc}
\hline Preference ø & $x_{1}$ & $x_{2}$ & $x_{3}$ & $x_{4}$ & Order \\
\hline$\tau=0.1$ & 0.1875 & 0.0667 & 0.5392 & 0.9833 & $x_{4}>x_{3}>x_{1}>x_{2}$ \\
$\tau=0.3$ & 0.3681 & 0.2001 & 0.5305 & 0.9500 & $x_{4}>x_{3}>x_{1}>x_{2}$ \\
$\tau=0.5$ & 0.5486 & 0.3335 & 0.5218 & 0.9167 & $x_{4}>x_{1}>x_{3}>x_{2}$ \\
$\tau=0.7$ & 0.7292 & 0.4669 & 0.5131 & 0.8833 & $x_{4}>x_{1}>x_{3}>x_{2}$ \\
$\tau=0.9$ & 0.9097 & 0.6003 & 0.5044 & 0.8500 & $x_{1}>x_{4}>x_{2}>x_{3}$ \\
\hline
\end{tabular}

From Table 10, the ranking of suppliers is different based on the preferences $(\tau)$ of the decision maker. Specifically, when the decision maker has a service quality preference $(\tau<0.5)$, supplier $x_{4}$ is the best and $x_{2}$ is the worst. When the decision maker has a cost preference ( $\left.\tau>0.5\right)$, supplier $x_{4}$ or $x_{1}$ is the best and $x_{2}$ or $x_{3}$ is the worst. The ranking of suppliers also differs based on the preference degrees of decision makers, as shown in Figure 1.

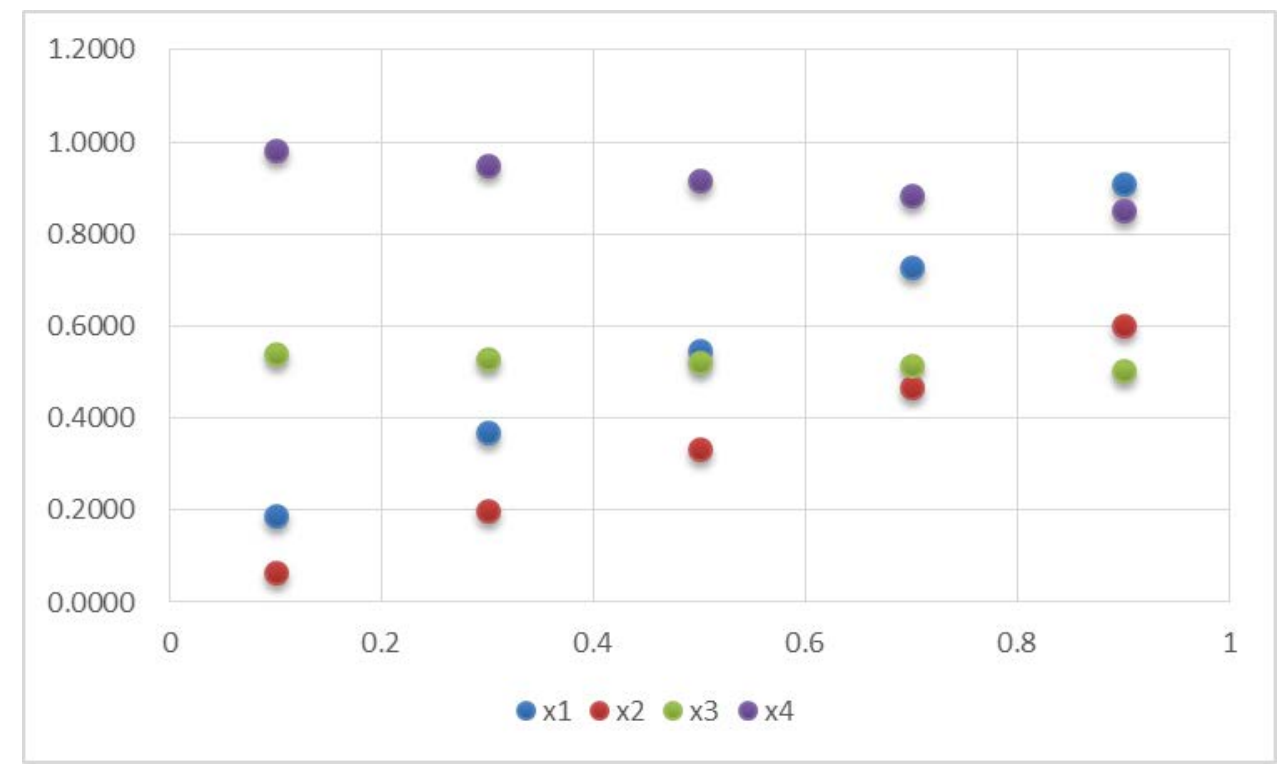

Figure 1. Ranking of suppliers with different preference degrees.

\section{Discussion and Conclusions}

Supplier selection has been the subject of significant research. However, most previous studies aimed at quantifying supplier selection as an optimization target and did not pay significant attention to combining non-quantifiable and quantifiable modeling processes. Furthermore, for the service quality evaluation of suppliers, most previous studies did not consider the psychological behavior of experts. To solve these problems, a preference model for supplier selection based on HFS was proposed in this paper. The proposed model analyzes the cost and service quality of suppliers while 
considering the preferences of decision makers. For the non-quantifiable quality of service, HFS are used to describe the evaluations of experts. In this service quality assessment process, TODIM is used to represent the individual psychological behaviors of experts. Using the proposed model, suppliers can be ranked based on the differing preferences of decision makers to determine the best supplier. Finally, a numerical example of supplier selection for high-end equipment manufacturing was presented to verify the proposed model.

In the illustrative example of high-end equipment manufacturer supplier selection, cost and service quality were considered. Some significant results of this case study can be summarized as follows:

(1) The proposed model considers the preferences and behavior of the decision maker. As a result, their needs are more accurately reflected based on their preference for cost or service quality.

(2) The supplier service quality assessment considers the hesitation of expert assessments and psychological behavior. The supplier service assessment based on HFS and TODIM is an important input for the proposed preference model.

The supplier selection problem is of paramount importance in the modern commercial economy. However, improving supplier ranking involves many factors and poses difficulties for decision makers. The main purpose of the proposed model for supplier selection is to accurately represent the preferences of decision makers. Furthermore, supplier selection primarily considers cost and service quality, where service quality includes many attributes. Therefore, supplier selection is an important and challenging problem.

To solve the problems outlined above, a preference model based on HFS was proposed to select a supplier and a case study was presented to verify the effectiveness of the proposed model. However, the attributes for supplier service quality evaluation were simplified to some extent. Therefore, as a next step, more complex attributes could be obtained to evaluate supplier selection using a more comprehensive preference model.

Acknowledgments: We are thankful to the Editor and 1the reviewers for their valuable comments and detailed suggestions to improve the presentation of the paper. Further, we also acknowledge the support in part by the National Natural Science Foundation of China under grant No. 71690233, No. 71671186 and No. 71401167.

Author Contributions: Zhexuan Zhou designed the model and performed the experiments; Yajie Dou and Yuejin Tan analyzed the data; Yajie Dou and Tianjun Liao contributed reagents/materials/analysis tools; Zhexuan Zhou wrote the paper.

Conflicts of Interest: The authors declare no conflict of interest.

\section{References}

1. Dong, J.F.; Wang, G.; Lv, M.; Gao, G.A. Multi-supplier selection problem solution based on improved ant colony algorithm. Comput. Integr. Manuf. Syst. 2007, 13, 1639-1644.

2. Groot, A.M.; Groot, A.M., Jr. Economic order quantity. Hosp. Prog. 1964, 3, 162-164.

3. Dickson, G.W. An analysis of vendor selection systems and decision. J. Purch. 1966, 2, 1377-1382. [CrossRef]

4. Degraeve, Z.; Labro, E.; Roodhooft, F. An evaluation of vendor selection models from a total cost of ownership perspective. Eur. J. Oper. Res. 2000, 125, 34-58. [CrossRef]

5. Karpak, B.; Kumcu, E.; Kasuganti, R.R. Purchasing materials in the supply chain: Managing a multi-objective task. Eur. J. Purch. Supply Manag. 2001, 7, 209-216. [CrossRef]

6. Buffa, F.P.; Jackson, W.M. A goal programming model for purchase planning. J. Supply Chain Manag. 1983, 19, 27-34. [CrossRef]

7. Ghodsypour, S.H.; O'Brien, C. A decision support system for supplier selection using an integrated analytic hierarchy process and linear programming. Int. J. Prod. Econ. 1998, s56-s57, 199-212. [CrossRef]

8. Rodger, J.A. Forecasting of Radio Frequency Identification Entropy Viscosity Parking and Forwarding Algorithm Flow Risks and Costs: An Integrated Supply Chain Health Manufacturing System (ISCHMS) Approach. IEEE J. Radio Freq. Identif. 2017, 1, 267-278. [CrossRef] 
9. Byun, D.H. The AHP approach for selecting an automobile purchase model. Inf. Manag. 2001, 38, $289-297$. [CrossRef]

10. Tam, M.C.Y.; Tummala, V.M.R. An application of the ahp in vendor selection of a telecommunications system. Omega 2001, 29, 171-182. [CrossRef]

11. Stefanović, M.; Aleksić, A.; Tadić, D. The evaluation and ranking of medical device suppliers by using fuzzy TOPSIS methodology. J. Intell. Fuzzy Syst. 2014, 27, 2091-2101.

12. Yu, M.; Qi, X.; Shen, G. Research on the supplier selection model of closed-loop logistics systems with hesitant fuzzy information ${ }^{1}$. J. Intell. Fuzzy Syst. 2016, 30, 3431-3437. [CrossRef]

13. Zhou, G. Research on supplier performance evaluation system based on data mining with triangular fuzzy information. J. Intell. Fuzzy Syst. 2016, 31, 2035-2042. [CrossRef]

14. Gupta, P.; Mehlawat, M.K.; Grover, N.; Chen, W. Modified intuitionistic fuzzy SIR approach with an application to supplier selection. J. Intell. Fuzzy Syst. 2017, 32, 4431-4441. [CrossRef]

15. Cao, Q.; Wu, J.; Liang, C. An intuitionsitic fuzzy judgement matrix and TOPSIS integrated multi-criteria decision-making method for green supplier selection. J. Intell. Fuzzy Syst. 2015, 28, 117-126.

16. Bohner, C.; Minner, S. Supplier selection under failure risk, quantity and business volume discounts. Comput. Ind. Eng. 2017, 104, 145-155. [CrossRef]

17. Wan, S.; Xu, G.; Dong, J. Supplier selection using ANP and ELECTRE II in interval 2-tuple linguistic environment. Inf. Sci. 2017, s385-s386, 19-38. [CrossRef]

18. Barrio, M.A.O.; Felice, F.D.; Negrete, K.P.; Romero, B.A.; Arenas, A.Y.; Petrillo, A. An AHP-TOPSIS integrated model for selecting the most appropriate tomography equipment. Int. J. Inf. Technol. Decis. Mak. 2016, 15, 861-885. [CrossRef]

19. Zhao, H.; Guo, S. Selecting green supplier of thermal power equipment by using a hybrid MCDM method for sustainability. Sustainability 2014, 6, 217-235. [CrossRef]

20. Yazdanichamzini, A.; Yakchali, S.H.; Zavadskas, E.K. Using a integrated mcdm model for mining method selection in presence of uncertainty. Econ. Res.-Ekon. Istraž. 2012, 25, 869-904.

21. Kavilal, E.G.; Venkatesan, S.P.; Kumar, K.D.H.; Eggert, R.G. An integrated fuzzy approach for prioritizing supply chain complexity drivers of an indian mining equipment manufacturer. Resour. Policy 2017, 51, 204-218. [CrossRef]

22. Zadeh, L.A. Fuzzy sets. Inf. Control 1965, 8, 338-353. [CrossRef]

23. Bellman, R.E.; Zadeh, L.A. Decision-making in a fuzzy environment. Manag. Sci. 1970, 17, B141-B164. [CrossRef]

24. Torra, V. Hesitant fuzzy sets. Int. J. Intell. Syst. 2010, 25, 529-539. [CrossRef]

25. Xia, M.; Xu, Z. Hesitant fuzzy information aggregation in decision making. Int. J. Approx. Reason. 2011, 52, 395-407. [CrossRef]

26. Farhadinia, B. A Novel Method of Ranking Hesitant Fuzzy Values for Multiple Attribute Decision-Making Problems. Int. J. Intell. Syst. 2013, 28, 752-767. [CrossRef]

27. Farhadinia, B. A series of score functions for hesitant fuzzy sets. Inf. Sci. 2014, 277, 102-110. [CrossRef]

28. Zhang, X.; Xu, Z. The TODIM analysis approach based on novel measured functions under hesitant fuzzy environment. Knowl.-Based Syst. 2014, 61, 48-58. [CrossRef]

29. Zhang, X.; Xu, Z. Hesitant fuzzy QUALIFLEX approach with a signed distance-based comparison method for multiple criteria decision analysis. Expert Syst. Appl. 2015, 42, 873-884. [CrossRef]

30. Xu, Z; Zhang, X. Hesitant fuzzy multi-attribute decision making based on TOPSIS with incomplete weight information. Knowl.-Based Syst. 2013, 52, 53-64. [CrossRef]

31. Zhang, X.; Xu, Z. Novel distance and similarity measures on hesitant fuzzy sets with applications to clustering analysis. J. Intell. Fuzzy Syst. 2015, 28, 2279-2296.

32. Ai, F.; Yang, J.; Zhang, P. An approach to multiple attribute decision making problems based on hesitant fuzzy set. J. Intell. Fuzzy Syst. 2014, 27, 2749-2755.

33. Tang, S.L. Green supplier selection model with hesitant fuzzy information. J. Intell. Fuzzy Syst. 2017, 32, 189-195. [CrossRef]

34. Selig, G.J. Implement IT Governance Methodology, Models, and Global Best Practices; China Economic Press: Taiyuan, China, 2011. 
35. Kłosowski, G.; Gola, A. Risk-based estimation of manufacturing order costs with artificial intelligence. In Proceedings of the 2016 Federated Conference on Computer Science and Information Systems (FEDCSIS), Gdansk, Poland, 11-14 September 2016; Ganzha, M., Maciaszek, L., Paprzycki, M., Eds.; IEEE: Piscataway, NJ, USA, 2016; pp. 729-732. [CrossRef]

36. Xu, Z.; Xia, M. Distance and similarity measures for hesitant fuzzy sets. Inf. Sci. 2011, 181, $2128-2138$. [CrossRef]

37. Zhang, X. Multiple Attribute Decision Making Method Based on Fuzzy Information Hesitation Research. Ph.D. Thesis, Southeast University, Dhaka, Bangladesh, August 2015.

38. Liao, H.; Xu, Z. A VIKOR-based method for hesitant fuzzy multi-criteria decision making. Fuzzy Optim. Decis. Mak. 2013, 12, 373-392. [CrossRef]

39. Gomesab, L.F.A.M. An application of the TODIM method to the multi-criteria rental evaluation of residential properties. Eur. J. Oper. Res. 2009, 193, 204-211.

(C) 2018 by the authors. Licensee MDPI, Basel, Switzerland. This article is an open access article distributed under the terms and conditions of the Creative Commons Attribution (CC BY) license (http:/ / creativecommons.org/licenses/by/4.0/). 